\title{
Strategic sourcing of marketing content
}

\author{
Hanna-Maija Nyberg \\ was invited by Nordic and Baltic telecommunications leader Sonera to develop a new business model to bring more consistency and \\ efficiency to marketing in 1999. Since Sonera and Telia merged, she has led Sales \& Marketing Corporate Sourcing. Previously, Hanna- \\ Maija managed McCann-Helsinki's advertising production and below the line group.
}

Keywords: strategic partnering, unified workflow, supply chain, procurement automation, automated campaign reports, learning by example

Abstract Supply chain management is significant for brand owners simply because the global market situation requires the rapid execution of marketing campaigns. Faster time to market is essential, especially for enterprises operating in several countries or regions.

Companies meet new challenges with brand consistency and cost control. Without standardized workflows and tight cost control, the campaign localization process is inefficient, takes too much time, causes uncertainty in output quality and is more expensive. There is a clear need for tools to ensure output quality and to control the costs. A unified, transparent process through the supply chain is the key to collecting the necessary information, speeding up campaign launches and gathering reliable reports for businesses' use. TeliaSonera's Marketing eTools solve the pain points in brand management, give necessary tools for operative work and bind the supplier chain in a unified, transparent and measurable workflow. TeliaSonera Finland shares the campaign creation, execution and measurement process with the partners - creative agencies, research, event and all production companies. Since beginning this workflow four years ago, Marketing eTools has provided benefits and bonuses for TeliaSonera as it has been used by both marketing and partners.

Hanna-Maija Nyberg TeliaSonera Finland Oyj Teollisuuskatu 15 , PL154, 00051 Sonera, Helsinki, Finland Tel: +358405062561 Email: Hannamaija.nyberg@teliasonera.com

\section{THE BENEFITS OF STRATEGIC PARTNERING}

Today's global market situation challenges enterprises in a new way. The accelerated marketing cycle - especially simultaneous launches of campaigns in different market areas - poses completely new challenges for buying services and for monitoring results. The greatest challenges to a company's marketing function relate to ensuring brand consistency in all areas and all channels, management of total costs and schedules, and efficient use of available resources.

Marketing operations are often interdependent yet not systematically integrated. The result is a high degree of inefficiency and, more

importantly, slow response to customer demands and market conditions. Relating these functions requires a comprehensive systems approach that manages all marketing processes: planning, project management, budgeting, scheduling, tracking/reporting, digital asset management, and uniform sourcing.
This model sets high requirements for the enterprise's marketing function: it must change its practices, review and unify its processes, create common rules both for marketing and for cooperation with all external partners, and make everyone committed to the company's way of operating. This helps the company create a model where each partner has a role defined by the service buyer, where optimum resourcing is achieved, and where the workflow has been clarified by means of predetermined responsibilities throughout the supply chain.

\section{UNIFIED WORKFLOW THROUGH THE SUPPLY CHAIN}

Marketing is one of the most variable business processes in any enterprise, both from industry to industry and company to company. The nature of an organization's marketing processes is tightly linked to their products or services, channels, markets, and brand, when compared 
Project info | Objectives | Briefs | Creative plan | Media plan | Budget and costs | Production

\section{Mobile Summer campaign 1745}

\begin{tabular}{|c|c|c|}
\hline$\frac{\text { Top level }}{\text { info }}$ & & \\
\hline \multicolumn{3}{|l|}{ Project settings } \\
\hline Project name & Mobile Summer campaign & EOXT \\
\hline Project level & Media & \\
\hline Project creator & Andrew Hannah & \\
\hline Products / Services & Mobile products & EDX \\
\hline Country & Finland & \\
\hline Regions / Dealership & $\begin{array}{l}\text { Sweden } \\
\text { Norway }\end{array}$ & \\
\hline Overall objective & $\begin{array}{l}\text { Activate SMS and MMS services in up to } 20 \% \text { of } \\
\text { target group. }\end{array}$ & EDX \\
\hline Main message & \multicolumn{2}{|c|}{ Sonera's new mobile services are simple to activate and easy to use. } \\
\hline Project timing & \multicolumn{2}{|l|}{$\underline{10.01 .2002}-\underline{10.08 .2002}$} \\
\hline Media advertising (Top level) & & EDYT \\
\hline Sonera Responsible & Andrew Hannah & \\
\hline Channels / Types & $\begin{array}{l}\text { - Print } \\
\text { - Internet } \\
\text { - TV }\end{array}$ & \\
\hline \multirow[t]{2}{*}{ Target group \& segment } & $\mathrm{B} 2 \mathrm{C}$ & \multirow[t]{2}{*}{ EDIT } \\
\hline & $\begin{array}{l}\text { - Seniors } \\
\text { - Dealers } \\
\text { - Partners }\end{array}$ & \\
\hline \multicolumn{2}{|l|}{ Direct marketing (Sub campaign) } & \multirow[t]{3}{*}{ EDXT } \\
\hline Sonera Responsible & Jane Grey & \\
\hline Channels / Types & $\begin{array}{l}\text { - e-mail } \\
\text { - Wireless } \\
\text { - Print }\end{array}$ & \\
\hline \multirow[t]{2}{*}{ Target group \& segment } & $\mathrm{B} 2 \mathrm{C}$ & \multirow[t]{2}{*}{ EOXT } \\
\hline & $\begin{array}{l}\text { - Seniors } \\
\text { - Dealers } \\
\text { - Partners }\end{array}$ & \\
\hline \multicolumn{2}{|l|}{ Project team } & EOXT TEAM \\
\hline \multicolumn{2}{|l|}{ Sonera Sales \& Marketing } & EDIT MESSANKM \\
\hline$\underline{\text { Luis Red }}$ & \multicolumn{2}{|l|}{ Marketing director } \\
\hline Christine Blue & \multicolumn{2}{|l|}{ Marketing manager } \\
\hline \multicolumn{2}{|l|}{ Ad. agency } & \multirow[t]{2}{*}{ EDIT MESSAGKG } \\
\hline Eric Orange & Project director & \\
\hline Lily Green & Project director & \\
\hline
\end{tabular}

Figure 1: Project summary - TeliaSonera Marketing eTools system streamlines the workflow process across entire groups of users and organizations and eliminates the frequent redundancies that hinder the speed and consistency of many marketing processes 
Active projects | Published projects | Projects on hold | Cancelled projects

Projects

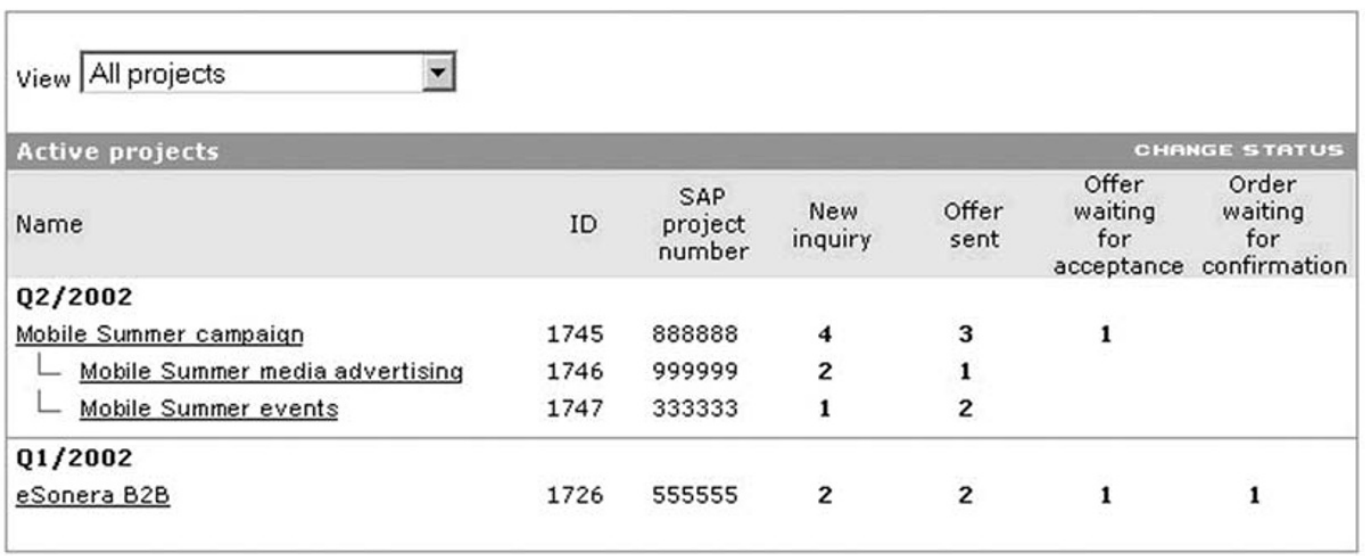

Figure 2: Project structure - A listing of the number of inquiries, offers, and orders is indicated for each project and sub-project to allow production partner sales teams a quick overview of each project's status

with that of finance or manufacturing.

Enterprise marketing services must easily adapt to any number of marketing organizational structures and processes.

To date, advertising agencies have taken care of the advertisers' materials, rights and purchases from subcontractors. In the future, it will be necessary for an enterprise to manage the marketing process and the supply chain to be able to leverage the measurements of advertising effectiveness - both successes and failures - in business planning.

Although companies have invested in systems for customer relationship management, enterprise resource planning (ERP), content management, and digital asset management (DAM), the marketing processes, resources, partners and measurement methods of many companies still allow the supply partners great liberty and are based on interpersonal agreements rather than on a uniform conceptual model established by the companies. Even most of the larger corporations lack commensurable tools and methods. This results in overlapping work, and costs both time and money, as previously produced information cannot be utilized further in business planning. The truth is, however, that in future, no one can afford overlapping processes, as the speed of the marketing cycle will be the most significant competitive factor in the global market economy.

TeliaSonera's Marketing eTools system (see Figures 1-8) represents a business strategy for accelerating business process cycle times. Depending on the nature of the cycle times required for different business models, enterprises will reap the interrelated benefits of improved time-to-market, process improvements, and cost reductions. Businesses whose revenues reflect short-term marketing investments (consumerpackaged goods, entertainment, automotive, consumer electronics etc) achieve the best possible return on investment (ROI) due to the time critical nature of their operations. However, even organizations whose businesses derive revenues from long-term contracts or long-cycle infrastructure products, where timeto-market is less critical, still reap a positive ROI through process improvements and cost reductions alone.

The Marketing eTools system is an everyday tool for TeliaSonera's marketing function and its partners, and it is used for carrying out all marketing and communications projects. The system contractually ties the different parties to a process defined by TeliaSonera - a process where everyone has a clearly defined role and responsibility. The system was introduced in 2001, and since then, 
Create new project $(1 / 6)$

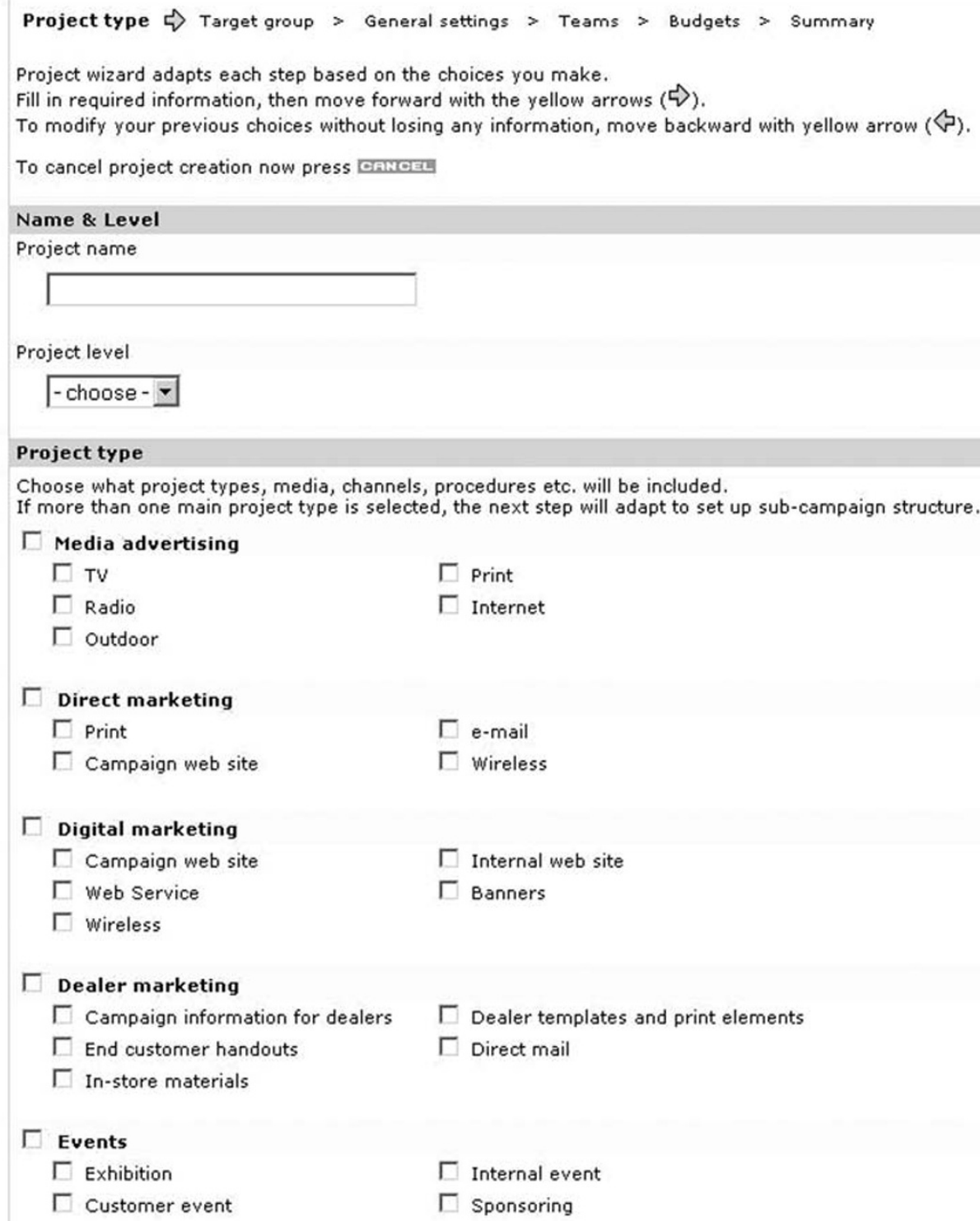

Figure 3: Project definition - Users can freely move backward and forward through the different phases of the project definition form without losing any input data

the cost savings and optimal use of resources achieved by the process have received ample praise not only from TeliaSonera employees but also from external partners (creative and media partners, production, research and event companies, etc).

Key benefits achieved by the Marketing eTools system include:
- real-time information channel for all project members;

- centralized database for compiling information on project participants, materials produced, costs, results, surveys conducted, and market analyses;

- continuous development of the process in order to support business operations, to save 


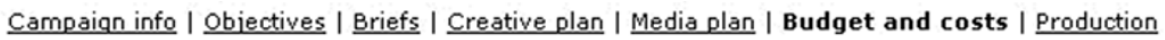

Mobile Summer campaign 1746

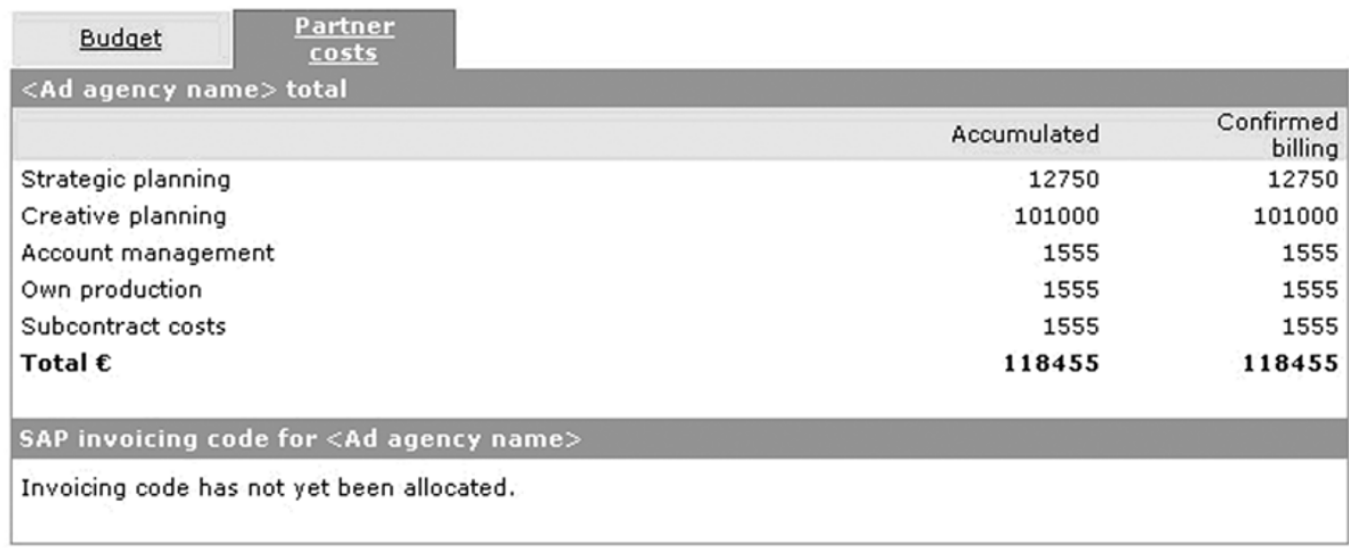

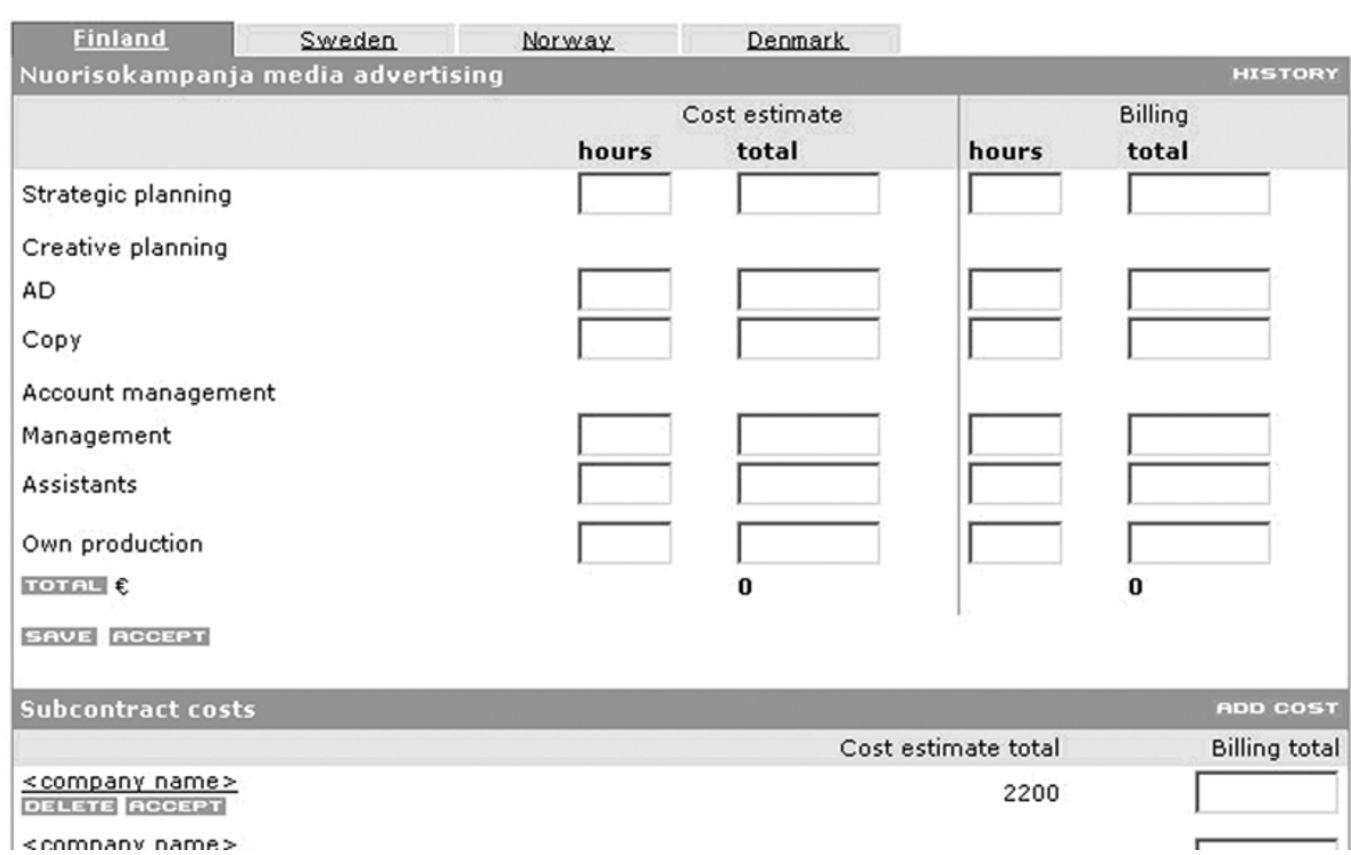

Figure 4: Cost structure - Each partner organization is assigned a specific cost structure whenever that partner is associated with a project. Business logic reads the appropriate cost structure from the data structure and creates a cost form visible only to that particular partner and the internal project team via the partner costs interface.

resources, and to provide real-time information for planning purposes.

Partner network:

- each partner has a contractually defined role and responsibility;

- partners have received training related to the brand and the marketing concept;
— procurement process (request for quotation (RFQ) offer, order, billing);

- uniform and comparable pricing regime;

— standardized workflow.

Uniform marketing metrics:

— uniform budgeting and target-setting; 


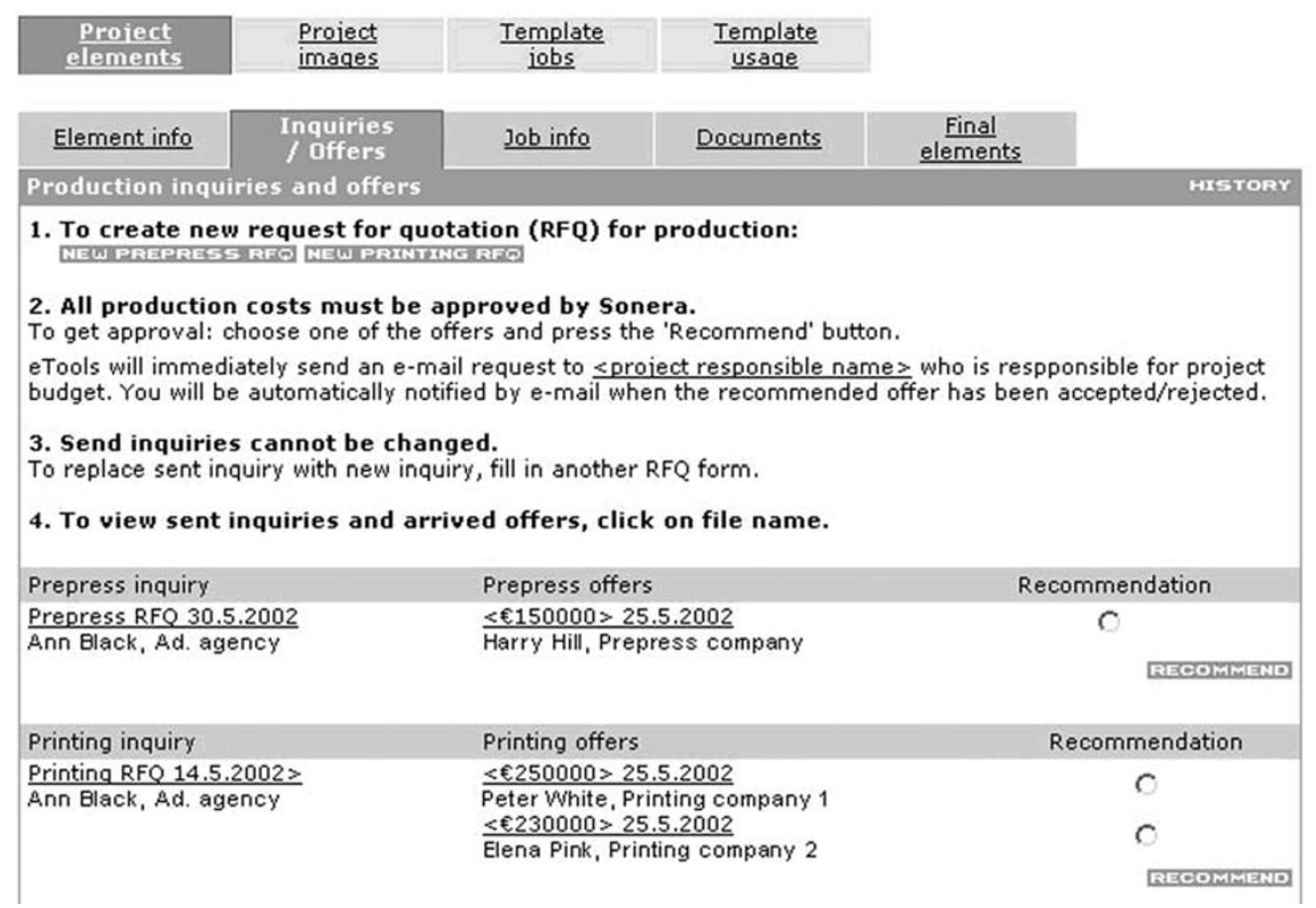

Figure 5: RFQ - offer - Marketing eTools sourcing processes generate inquiries based on the media type and thereby contains all necessary information for the production partners. Once the inquiry is completed the system requires three partners to be chosen from a list automatically generated from the pool of appropriate partners. The partners fill in the cost and information fields in the offer form and once an offer is accepted by the customer, it is immediately added to the accepted cost estimate total for that particular production partner as well as in the total accepted cost estimates.

- uniform effectiveness metrics means comparable group-level reporting;

- monitoring of marketing costs and effectiveness as part of business planning;

- uniform way of assessing and developing the competence of the marketing personnel.

\section{PROCUREMENT AUTOMATION}

Enterprises buy marketing services on a turnkey principle. Fragmented purchases from subcontractors are made on behalf of the enterprises by creative agencies with competence and understanding of various production techniques and their requirements. Most companies do not have marketing purchasers who master new graphic nor digital technology in all of its various forms or specialists in the field, but usually they trust the choices made by their partners. The larger the number of countries in which an enterprise markets its products, the more important the management of the subcontractor network is. An average campaign includes 25-30 elements. If the marketing is targeted to ten countries, how the 250-300 different advertisement or brochure versions are produced is highly significant.

The Marketing eTools system provides a tool for the management of the entire sourcing process: RFQ, offer, order, confirmation and billing. The different steps of the purchase process are available transparently and in real time to the enterprise's marketing function, where the person responsible for the campaign approves the partner's choice and the related costs, via the system. The costs, production steps and documentation are collected in a centralized archive during the project and automatically subjected to real-time monitoring. This allows the enterprise to utilize all the information in the future without having to use the same supplier. A uniform process guarantees independence of suppliers in the production of materials.

Producing 250-300 material versions using predetermined sourcing processes within 


\section{Research - Main result:}

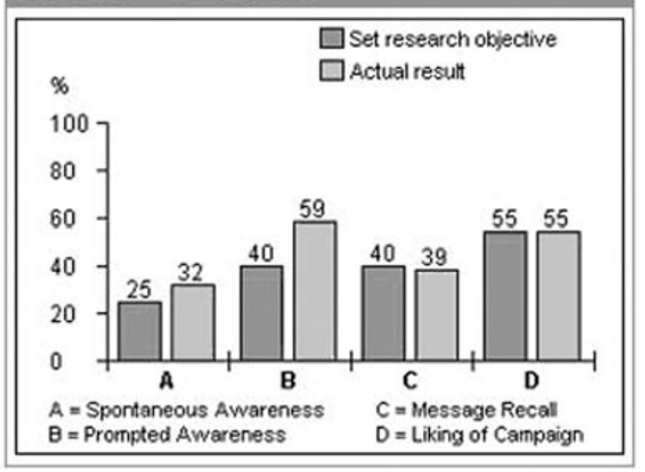

Figure 6: Metrics and research - Marketing eTools Metrics section provides a real-time, cost-benefit assessment and efficiency reporting of all marketing projects, up-to-the-minute marketing calendar, and access to additional materials like general market analyses and research reports

centralized data system brings savings of about 30-50 per cent of production costs.

\section{AUTOMATED CAMPAIGN REPORTS}

To succeed in global markets in the future, an enterprise should define common metrics for marketing and create a concept for project workflow to which strategically selected partners can be connected. This is a prerequisite for reliable reporting that provides the enterprise's business with genuine added value and enables the enterprise to react much faster to changes in market conditions and to take the required marketing measures more rapidly. The only way an enterprise can justify the ROI of its marketing investments and react sufficiently quickly to market demands is by creating models and concepts for a uniform process from planning and implementation of projects to metrics. In the Marketing eTools system, reporting is an integral part of the process. Information is automatically transmitted to a follow-up report regardless of the point of the workflow at which the information to be monitored is entered. In most cases, information is compiled in the report piece by piece, based on the information provided by external partners. This is the case, for example, in the monitoring of partner costs. A real-time monitoring tool makes it easier to monitor costs, but its greatest added value lies in the fact that campaign results can be integrated with business planning, ie closing the loop.

\section{LEARNING BY EXAMPLE}

The most important thing for a person responsible for an enterprise's brand to ensure is brand consistency in all marketing communications. This is definitely as important as campaign metrics, effectiveness and results for an enterprise's CMO.

How could we then ensure brand consistency in global campaigns and achieve maximum effectiveness with optimum input without a common process that originates from the enterprise and engages all partners?

The most efficient way is unlikely to be a dispersed management model. Is it even realistic in practice to expect to receive reliably reported information from different parts of the world? After all, we do tend to see things from our own perspective, making the best of them.

When I started to develop the Marketing eTools concept at the turn of 1998-99, my aim was to build a centralized picture bank for TeliaSonera's marketing function. I soon came to realize, however, that what the company needed was a shared channel for distributing information and a common communications tool. To develop the procurement competence in business units we needed a common purchaser-independent model for dealing with partners. We started to unify our processes and train our personnel, and Marketing eTools was launched in October 2001, to cover the whole marketing process - planning, projects and follow-up - and to compile all the information in a centralized database.

Today, hardly anyone at TeliaSonera would be willing to carry out a project without Marketing eTools - it is the key tool for compiling and distributing information. About 95 per cent of all marketing operations are carried out by means of Marketing eTools. The system has 700 users in Finland alone. The process will certainly develop and change according to TeliaSonera's needs, but the framework will remain unchanged: a uniform process for marketing, partnering and measuring. 


\begin{tabular}{|c|c|c|c|c|}
\hline $\begin{array}{c}\text { Telecom } \\
\text { News }\end{array}$ & $\frac{\text { Sonera market }}{\underline{\text { analysis }}}$ & $\begin{array}{l}\text { Brand } \\
\text { research }\end{array}$ & $\begin{array}{l}\text { Customer } \\
\text { satisfaction }\end{array}$ & \\
\hline \multicolumn{5}{|l|}{ Reports } \\
\hline Name & \multicolumn{3}{|c|}{ Owner } & Publishing time \\
\hline Report1 & \multicolumn{3}{|c|}{ Andrew Hannah } & 24.12 .2002 \\
\hline Report2 & \multicolumn{3}{|c|}{ Andrew Hannah } & 24.12 .2002 \\
\hline Report3 & \multicolumn{3}{|c|}{ Andrew Hannah } & 24.12 .2002 \\
\hline
\end{tabular}

Figure 7: Up to date market analysis and research information for marketing management

\section{Nuorisokampanja 1486 PRODUCTION}

\begin{tabular}{|c|c|c|c|}
\hline $\begin{array}{c}\text { Project } \\
\text { elements }\end{array}$ & $\frac{\text { Project }}{\text { images }}$ & $\frac{\text { Template }}{\text { iobs }}$ & $\frac{\text { Template }}{\text { usage }}$ \\
Job tickets
\end{tabular}

Click on job ticket name to see details and materials.

\begin{tabular}{|c|c|c|c|c|c|}
\hline Brochure & Inquiry & Offer & $\begin{array}{c}\text { Recommended } \\
\text { to Sonera }\end{array}$ & $\begin{array}{c}\text { Offer } \\
\text { accepted }\end{array}$ & $\begin{array}{l}\text { Order } \\
\text { confirmed }\end{array}$ \\
\hline \multicolumn{6}{|l|}{ e-Sonera brochure } \\
\hline \multicolumn{6}{|l|}{$L$ Prepress work } \\
\hline \multicolumn{6}{|l|}{$L$ Printing work } \\
\hline \multicolumn{6}{|l|}{ DELETE } \\
\hline \multicolumn{6}{|l|}{ e-Sonera brochure } \\
\hline \multicolumn{6}{|l|}{ L Prepress work } \\
\hline \multicolumn{6}{|l|}{$L$ Printing work } \\
\hline \multicolumn{6}{|l|}{ DहसEलाE } \\
\hline Poster & Inquiry & Offer & $\begin{array}{c}\text { Recommended } \\
\text { to Sonera }\end{array}$ & $\begin{array}{l}\text { Offer } \\
\text { accepted }\end{array}$ & $\begin{array}{l}\text { Order } \\
\text { confirmed }\end{array}$ \\
\hline \multicolumn{6}{|l|}{ Sonera poster } \\
\hline$L$ Prepress work & & & & & \\
\hline L Printing work & 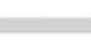 & & & & \\
\hline
\end{tabular}

Figure 8: Uniform processes and metrics in procurement speed up the delivery time and secure the brand quality with less money 